\title{
Associations between psychological factors and health-related quality of life and global quality of life in patients with ALS: a systematic review
}

Annerieke C. van Groenestijn ${ }^{1}$, Esther T. Kruitwagen-van Reenen ${ }^{1}$, Johanna M. A. Visser-Meily', Leonard H. van den Berg ${ }^{2}$ and Carin D. Schröder ${ }^{1 *}$

\begin{abstract}
Objective: To systematically identify and appraise evidence on associations between psychological factors (moods, beliefs, personality) and Health-related QoL (HRQoL) and/or global QoL in patients with Amyotrophic Lateral Sclerosis (ALS).

Methods: A systematic review was conducted in several online databases (PsycINFO, EMBASE, PubMed and CINAHL) up to October 2015. Articles were included if they reported associations between psychological factors (moods, beliefs and personality) and HRQOL and/or global QoL in an ALS population. The search was limited to empirical studies, published in English, which provided quantitative data. The methodological quality of the included articles was assessed.

Results: In total, 22 studies were included. Mood was investigated in 14 studies, beliefs in 11 studies and personality in one study. Fifteen different psychological factors were extracted and assessed using 24 different measures. Twelve different QoL measures were used in the selected studies, subdivided into seven different HRQoL measures and five different global QoL measures. Higher levels of anxiety and depression appeared to be related to a poorer HRQoL, whereas a higher level of religiosity seemed to be associated with better global QoL. No conclusive associations were found for confusion-bewilderment (mood), spirituality, mindfulness, coping styles, hopelessness, perception of burden, cognitive appraisal (beliefs), neuroticism, extraversion, openness, agreeableness and conscientiousness (personality), due to insufficient or inconsistent evidence. Religiosity and spirituality appeared to become more positively associated over time.

Conclusions: Our results suggest that higher levels of anxiety and depression are related to a poorer HRQoL, whereas higher levels of religiosity appeared to be related to better global QoL. Associations might change during the disease course. This review supports the importance of psychological factors with regard to ALS care. Further research is needed to supplement the available evidence and to investigate how psychological factors can be modified to improve QoL.
\end{abstract}

Review registration number: PROSPERO 2015:CRD42015027303

Keywords: Amyotrophic Lateral Sclerosis, Quality of life, Health-related QoL, Global QoL, psychological factors, Moods, Beliefs, Personality

\footnotetext{
* Correspondence: C.P.Schroder-4@umcutrecht.nl

${ }^{1}$ Brain Center Rudolf Magnus and Center of Excellence for Rehabilitation

Medicine, University Medical Center Utrecht and De Hoogstraat

Rehabilitation, Utrecht, The Netherlands

Full list of author information is available at the end of the article
} 


\section{Background}

Amyotrophic Lateral Sclerosis (ALS) is a fatal, progressive, neurodegenerative disorder affecting motor neurons in the spinal cord, brainstem and motor cortex. Patients suffer progressive wasting and weakness of limb, bulbar and respiratory muscles, leading to inability to speak and swallow, respiratory failure and complete paralysis $[1,2]$. Currently, there is increasing awareness that ALS is also associated with non-motor findings, including behavioral and cognitive deficits $[3,4]$. Patients eventually die due to respiratory failure within three to five years after symptom onset [1]. The incidence of ALS shows little variation in Western countries, ranging from 1.5 to 2.7 per 100,000 person-years, [5] with an estimated lifetime risk of 1 in 400 [6]. To date, no curative treatment is available. Therefore, optimal treatment is based on symptom management and optimizing Quality of Life (QoL).

There is, as yet, no agreed-upon definition of QoL. The World Health Organization (WHO) defines QoL as a broad ranging concept affected in a complex way by the person's physical health, psychological state, level of independence, social relationships and their relationship to salient features of their environment' [7]. Burns et al. [8] have suggested that a distinction can be made between Health-related QoL (HRQoL) and global QoL in patients with ALS. Health-related QoL (HRQoL) is more narrowly defined than global QoL and seeks to address those aspects of self-perceived well-being that are related to or affected by the presence of disease or treatment [8]. Assessment of HRQoL typically includes physical, psychological and social domains. Each domain may include measures that assess the patient's perception of symptoms, ability to function and disability [9]. Global QoL reflects overall QoL as judged by the patient and takes into account other, non-medical concepts, such as family, support system and friends [8]. Assessing global QoL generally provides a broader picture of the impact of disease on an individual's life [9].

HRQoL declines during the course of the disease [10]. This is expected as HRQoL instruments are heavily weighted toward physical function, and thus inevitably decline over time as patients with ALS lose their abilities. In contrast, there is growing evidence that global QoL seems to remain at a stable level, even in patients with advanced ALS. Psychological processes like coping, reframing expectations and spiritual practice might contribute to a change in internal standards and values of QoL, ultimately resulting in unexpectedly high QoL, even in later disease stages $[11,12]$. QoL in patients with ALS seems to be determined more by psychological, existential and support factors than by physical health [13-16], implying that a broad range of factors is involved in adjusting to illness. Psychological factors in patients with ALS may be modifiable targets for interventions to improve QoL.
The impact of psychological factors such as neuroticism, coping, cognitive appraisals and mood on QoL has already been demonstrated in other chronic diseases $[17,18]$ and in other progressive neurological illnesses, such as Huntington's disease, Parkinson's disease and multiple sclerosis [19]. Differences have, however, been reported between these progressive neurological illnesses and ALS concerning the contribution of psychological factors to QoL [19], suggesting that the rapidly progressive disabling process of ALS requires a different psychological adaptation process.

Over the last decade, interest has grown in the relationships between psychological factors and QoL in patients with ALS and to date, three narrative reviews on this subject have appeared [20-22]. The authors summarized associations between QoL and depression $[20,21]$, anxiety [20], spiritual and existential issues [20-22], sense of burden [22] and hope/hopelessness $[20,22]$ in patients with ALS, but as they did not quantify or appraise them, the relationships remain unclear.

The present study aims to collect and appraise the available evidence on the associations between psychological factors and HRQoL and/or global QoL. Understanding the relationships between QoL and psychological factors and the contribution of these factors to either HRQoL or global QoL might help health professionals to develop adequate interventions in order to optimize QoL in patients with ALS.

\section{Methods}

This study was registered followed the PRISMA reporting guidelines (see online Additional file 1): http://journals.plos.org/plosmedicine/article?id=10.137 1/journal.pmed.1000097

\section{Procedure}

A search of online databases EMBASE, PsychINFO, PubMed and CINAHL was carried out up to October, 2015. No constraint was placed on the year of publication. The following MeSH headings and key words were used: 'amyotrophic lateral sclerosis' or 'motor neuron disease' in combination with 'psychological factors' (and synonyms including related terms, e.g. anxiety, depression, coping, religiosity and neuroticism) and 'quality of life' (and synonyms including related terms, e.g. well-being, value of life and perceived health). Additional file 2 provides an overview of the search strategy used in PubMed. Two authors (AvG, CS) independently checked the titles and abstracts on the selection criteria shown below, and compared their results. Concurrence between both researchers was calculated using Cohen's kappa [23]. At each step of the process, disagreement regarding selection was discussed and settled with reference to the explicit inclusion criteria. If, after discussion, no agreement could be reached, 
another author (JV) was consulted for a final judgment. The same procedure was followed for final in-or exclusion after reading full text articles. The reference sections of retrieved articles were searched to identify further studies suitable for inclusion.

\section{Quality assessment}

After the study selection, methodological quality was assessed independently by two researchers (AvG, EK) according to an 8-point checklist, resulting in a score that ranged from lowest quality (1) to highest quality (8) [17]. The level of agreement between the researchers' ratings was established using the Intraclass Correlation Coefficient (ICC).

\section{Eligibility criteria and operationalization of concepts}

The current review is restricted to empirical studies which provided quantitative data, thus excluding qualitative studies, reviews and case reports. Only studies of patients with ALS or providing separate data from patients with ALS were included, in which standardized measures were used to assess direct relationships between psychological factors (determinant) and a total QoL construct (outcome). Studies using a total score for HRQoL and global QoL, or a mental or physical component score of the HRQOL and / or a single-item score representing global QoL, were included. Thus studies describing associations between psychological factors and one subscale of a QoL measure were not taken into account. Furthermore, the review was limited to studies written in the English language that were published in peer-reviewed journals.

Psychological factors are part of the contextual factors (personal and environmental factors) defined by the International Classification of Disability, Functioning and Health (ICF) [24]. Psychological factors, such as coping styles, may play a role in disability at any level, but are not part of a health condition or health states [24]. In order to gain more insight into their association with HRQoL and/or global QoL, we have clustered the psychological factors into three main groups: mood, beliefs and personality. Mood is a generalized, internal state of feeling (e.g. anxiety, depression and anger) and is closely related to the concepts of affect and emotion. Beliefs refer to people's perceptions of reality including perceptions of health or illness and one's ability to cope with illness (e.g. attitudes, appraisals, religiosity and coping strategies). Personality can be defined as a dynamic and organized set of characteristics which a person possesses and which uniquely influence his or her beliefs, motivations and behaviour in various situations [25].

\section{Data extraction and analysis}

We collected information on study characteristics: author, country, sample size and study design, and patient characteristics: age at inclusion, the time of assessment since ALS onset, the functional status of patients (using the Amyotrophic Lateral Sclerosis Functional Rating Scale (ALSFRS), the diagnostic criteria and the type of ALS onset (spinal vs. bulbar). Furthermore, measures of global QoL and HRQoL and of psychological factors, as well as associations between psychological factors and QoL (Health-related and global) were extracted.

Bivariate and multivariate associations were described separately in terms of correlation coefficients $(r)$, standardized $\beta$-coefficients $(\beta)$ and the explained variance of the psychological factors $\left(R^{2}\right)$. The strength of correlation was described as follows: "weak" correlation $=0<|\mathrm{r}|<0.3$; "moderate" correlation $0.3<|\mathrm{r}|<0.5$; "strong" correlation $|\mathrm{r}|>0.5$ (Cohen, [23]). We classified the methodological quality of the studies to be "high" if they were above 5.5, "adequate" between 3.5 and 5.5, and "poor" below 3.5 .

Psychological factors were considered "consistent related" if (1) the majority (>50 \%) of all studies reported statistically significant bivariate and/or multivariate associations; (2) the majority of the bivariate associations were moderate or strong; and (3) the methodological quality of these studies was adequate or high.

\section{Results}

\section{Description of studies included}

The search strategy produced a total of 1040 articles (Fig. 1). After removing 153 duplicates, a further 830 articles were removed after screening title and abstract. Agreement on selection of titles and abstracts between the two raters was high (Cohen's kappa 0.82). A total of 57 articles remained for full-text screening; 22 articles met all inclusion criteria. The screening of reference lists produced one additional article [10]. In two studies $[16,26]$, the same cohort data was used; we included the study by Bremer because of a higher quality assessment.

The characteristics of the 22 included studies are presented in Table 1. Studies were published between 1999 and 2015; most were cross-sectional $(n=16)$; six used longitudinal data [16, 27-31]. The median sample size was $n=49$ (range 26-197). Studies concerned patients with a mean time of ALS onset between 11.7 months and 5.7 years; the disease severity ranged from 17.4 (severely impaired) to 35.1 points (moderately impaired). The mean age at inclusion varied between 55.3 and 64.0 years; a minority of the patients (7-33 \%) had a bulbar onset of ALS, and there was a slight male predominance (M:F ratio 1.5:1). These findings were consistent with those of the general ALS population (mean age 58-63 years; bulbar onset of $30 \%$ and M:F ratio 1.2-1.5:1) [32, 33].

Across the studies, fifteen different psychological factors were assessed using 24 different measures. The 


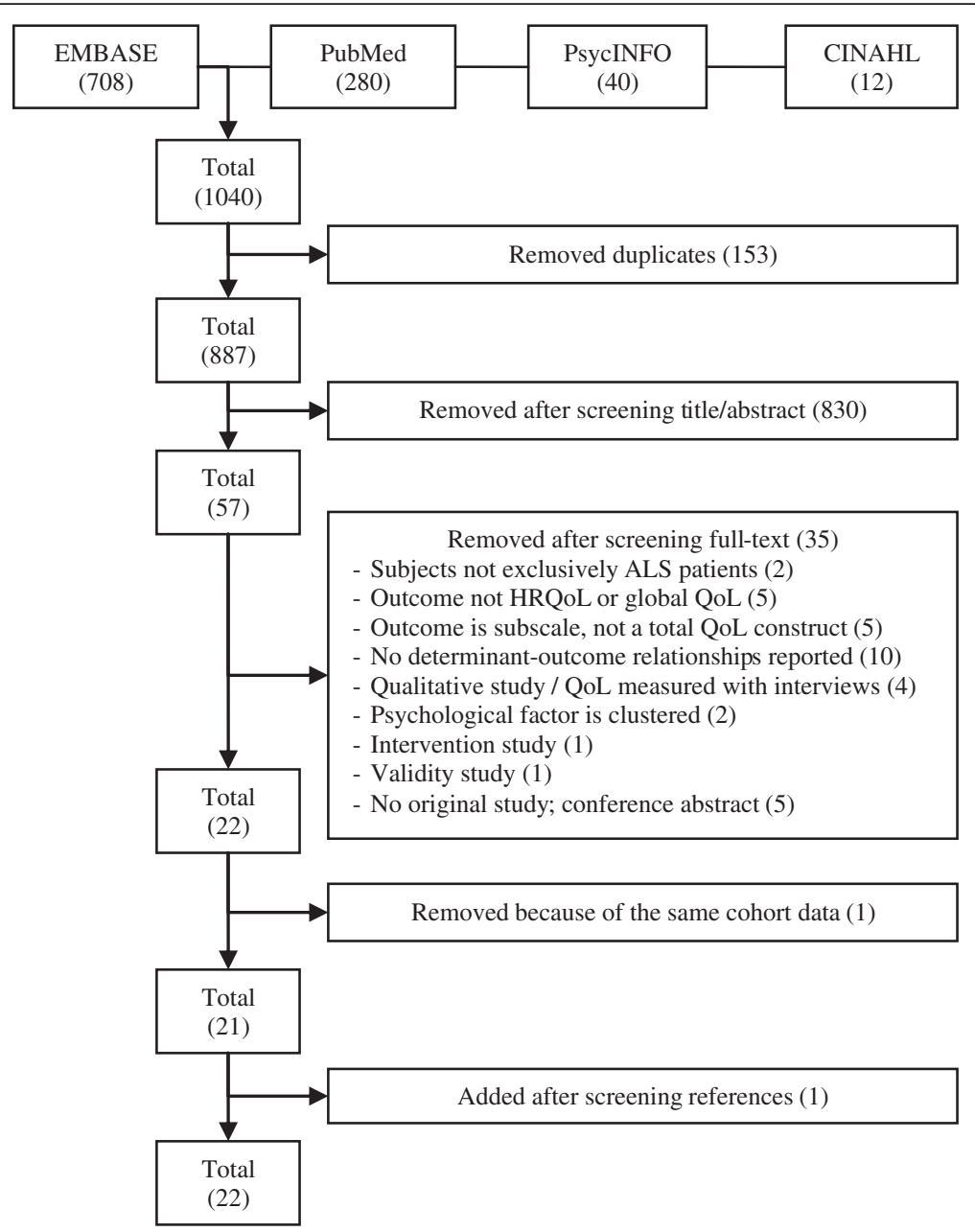

Fig. 1 Search flowchart

various instruments for assessing psychological factors are described in Table 2. Mood was investigated in 14 studies, beliefs in 11 and personality in one study. Two ALS-specific questionnaires, the ALS Depression Inventory (ADI-12) [34] and the Motor Neuron Disease Coping Scale (MNDCS) [35] were applied in one [28] and three $[30,36,37]$ studies, respectively. The modified versions of the Hospital Anxiety and Depression Scale (HADS), which were intended not to rely on measuring the physical components of depression, were used in two studies $[37,38]$ (Table 2).

A total of 12 different QoL measures were used in the selected studies, including five different Global QoL measures and seven different Health-related QoL measures (Table 3 and Table 4, resp.). One ALS-specific HRQoL questionnaire, the Sickness Impact Profile ALS (SIP/ALS-19) [39], was used in two studies [14, 31].

The average methodological quality score of the studies was 5.3 and ranged from 3 to 8 out of a maximum 8 points (Table 5). Seven studies (32\%) achieved a "high quality" score $(\geq 6 / 8)$. Inter-rater agreement on quality of the individual studies was high $(\mathrm{ICC}=0.90)$.

\section{Psychological factors associated with QoL in ALS}

An overview of the bivariate and multivariate associations between psychological factors and QoL is presented in Table 6. Due to the heterogeneity of instruments used in assessing both psychological factors $(n=24)$ and QoL $(n=12)$, a meta-analysis was not possible.

\section{Mood associated with QoL}

Concerning mood, relationships between QoL and anxiety, depression and confusion-bewilderment were found.

\section{Anxiety}

Six studies assessed the relationship between anxiety and QoL [15, 19, 37, 38, 40, 41]; three studies reported HRQoL and three global QoL.

Two out of three studies, including one high quality study [37] which used a modified HADS, showed 
Table 1 Patient and study characteristics

\begin{tabular}{|c|c|c|c|c|c|c|c|c|}
\hline \multirow[b]{2}{*}{ Author (date) } & \multicolumn{3}{|l|}{ Study characteristics } & \multicolumn{5}{|l|}{ Patient characteristics } \\
\hline & Country of research & $\begin{array}{l}\text { Sample size } \\
\mathrm{n} \text { (male } \mathrm{n} \text { ) }\end{array}$ & Design & Age in years & $\begin{array}{l}\text { Time since onset }(\mathrm{O}) / \\
\text { Time since diagnosis }(\mathrm{D})\end{array}$ & ALSFRS & $\begin{array}{l}\text { Diagnostic } \\
\text { criteria }\end{array}$ & $\begin{array}{l}\text { Onset } \\
\text { bulbar (\%) }\end{array}$ \\
\hline Bremer $(2004)^{T 0}[16]$ & U.S.A & $49(29)$ & Longitudinal & $57.8(13.0)$ & $34.9(13.2) \mathrm{mo}^{\circ}$ & $27.9(6.3)$ & El Escorial & $n \cdot m$ \\
\hline Chio (2004) [13] & Italy & $80(49)$ & Cross sectional & $59.8(12.6 ; 26-81)$ & $2.1(1.7 ; 1-7.8) \mathrm{yr}^{\circ}$ & $26.6(9.5 ; 3-38)$ & El Escorial & n.m. \\
\hline Clarke (2001) [15] & Ireland & $26(18)$ & Cross sectional & $63^{\mathrm{M}}(34-86)$ & $31.5(4-156)^{\mathrm{M}} \mathrm{mo}^{\mathrm{D}}$ & $22.5^{\mathrm{M}}(11-36)$ & El Escorial & $n \cdot m$ \\
\hline Dal Bello-Haas (2000) [47] & U.S.A & $60(38)$ & Cross sectional & $56.2(12.2)$ & n.m & n.m & El Escorial & n.m. \\
\hline Ganzini (1999) [45] & U.S.A. & $100(61)$ & Cross sectional & $54^{\mathrm{M}}(51.6-56.8)$ & $2.8(2.0-3.6)^{\mathrm{M}} \mathrm{yr}^{\mathrm{D}}$ & n.m & n.m & n.m \\
\hline Gibbons (2013) [37] & U.K. & $147(90)$ & Cross sectional & $61(11 ; 35-81)$ & n.m & $22.3(9.5 ; 4-48)$ & 'confirmed diagnosis' & n.m \\
\hline Goldstein (2002) [38] & U.K & $31(19)$ & Cross sectional & $64.0(11.9)$ & $15.9(5.2) \mathrm{mo}^{\mathrm{D}}$ & n.m & El Escorial & n.m \\
\hline Ilse (2015) [10] & Germany & $49(25)$ & Cross sectional & $63.8(10.0)$ & $35.1(36.3) \mathrm{mo}^{\circ}$ & $32.6(9.2)^{R}$ & El Escorial & $33 \%$ \\
\hline Krampe $(2008)^{\mathrm{TO}}$ [27] & Germany & $31(19)$ & Longitudinal & $60.3(10.4 ; 32.9-79.7)$ & $96.3(70.5 ; 22.4-330.4) w k^{O}$ & $27.0(6.6 ; 12-38)$ & El Escorial & $19 \%$ \\
\hline Lule $(2008)^{\mathrm{TO}}[28]$ & Germany & $39(19)$ & Longitudinal & n.m & $43.9(37.5 ; 0-170) \mathrm{mo}^{\mathrm{D}}$ & $19.9(21.1 ; 0-39)$ & El Escorial & n.m \\
\hline Matuz (2010) [36] & Germany & $27(15)$ & Cross sectional & $55.3(11.1 ; 35-73)$ & $36(4-129) \mathrm{mo}^{\mathrm{D}}$ & $17.4(9.8 ; 0-36)$ & 'by a neurologist' & $7 \%$ \\
\hline Matuz $^{\text {T0 }}$ (2015) [30] & Germany & $27(15)$ & Longitudinal & $55.3(11.1 ; 35-73)$ & $43.2(30.5 ; 4-129) \mathrm{mo}^{\mathrm{D}}$ & $17.4(9.8 ; 0-36)$ & El Escorial & $7 \%$ \\
\hline McCabe (2009) [19] & Spain & $120(72)$ & Cross sectional & $63.2(12.4)$ & $5.7(5.8)^{\circ} \mathrm{yr}$ & n.m & n.m & n.m \\
\hline Montel (2012) [46] & France & $49(26)$ & Cross sectional & $63(12)$ & $45(28) \mathrm{mo}^{\mathrm{O}}$ & $28.2(9.0)^{R}$ & El Escorial & $22 \%$ \\
\hline Pagnini $^{\text {T0 }}$ (2015) [29] & Italy USA & $197(115)$ & Longitudinal & a & a & $30.6(9.9)^{\mathrm{SA}}$ & 'self-declared' & n.m \\
\hline Peric (2010) [40] & Serbia & $74(45)$ & Cross sectional & $57(11)$ & $29(27) \mathrm{mo}^{\circ}$ & $34(8)^{R}$ & El Escorial & n.m. \\
\hline Pizzimenti (2013) [43] & Italy & $36(22)$ & Cross sectional & $63.7(10.9)$ & $22(14) \mathrm{mo}^{\mathrm{O}}$ & $35.1(8.7)$ & El Escorial & $22 \%$ \\
\hline Robbins $(2001)^{T 0}[31]$ & U.S.A & $60(32)$ & Longitudinal & $58.5(13.5 ; 27-83)$ & n.m & $28.1(6.3 ; 12-39)$ & El Escorial & n.m \\
\hline Simmons (2000) [14] & U.S.A & $96(52)$ & Cross sectional & $57.8(23-80)$ & 31.8 (2 mo-10 year) $\mathrm{mo}^{\circ}$ & $26.6(9-39)$ & 'met the criteria' & n.m \\
\hline Tramonti (2012) [42] & Italy & $40(30)$ & Cross sectional & $59.1(10.9 ; 34-84)$ & n.m & $20.8(8.3 ; 7-36)$ & n.m & n.m \\
\hline Vignola $(2008)^{\mathrm{TD}}[41]$ & Italy & $29(20)$ & Cross sectional & $63.6(7.8 ; 44-78)$ & $11.7(23.7 ; 2-43) \mathrm{mo}^{\circ}$ & $33.1(4.8 ; 22-39)$ & El Escorial & n.m \\
\hline Winter (2010) [44] & Germany & $37(21)$ & Cross sectional & $59.6(11.0)$ & $2.3(1.9) \mathrm{yr}^{\mathrm{O}}$ & $n . m$ & El Escorial & n.m \\
\hline
\end{tabular}

Abbreviations: $n . m$ not mentioned, $M$ median instead of mean, yr year, mo months, wk weeks, ALSFRS Amyotrophic Lateral Sclerosis Functional Rating Scale, $R$ ALSFRS-Revised, SA self-administered ALSFRS, TO data from Abbreviations: $n . m$ not mentioned, $M$ median instead of mean, yr year, mo mo

a time since diagnosis and age were reported in categories 
Table 2 Psychological factor measurements

Psychological factors Measurement and references

Scoring system

Generic/ALS- References

specific in this

of items

\begin{tabular}{ll}
\hline Anxiety & $\begin{array}{l}\text { Hamilton rating scale for anxie } \\
\text { (HAM-A) }\end{array}$
\end{tabular}
14

To assess the severity of symptoms of anxiety.

Each of the items contains a number of symptoms,

Hamilton (1959) [63] and each group of symptoms is rated on a scale.

5-point scale. Total scores for anxiety

Generic

range from 0 to 56.

<17: mild severity
18-24: mild to moderate severity

25-30: moderate to severe

Hospital Anxiety and Depression

$7 \quad$ To assess psychological distress in medically Scale subscale anxiety (HADS-a)

Zigmond (1983) [54]

ill patients. The instrument concentrates on the

ill patients. The instrument concentrates on the psychic rather than the somatic symptoms of
mood disorder in order to provide an assessment of mood independent of levels of physical disability in patients with medical illnesses.

Hospital Anxiety and Depression Scale subscale anxiety (HADS-a) modified version 1

Gibbons (2011) [56]

State and Trait Anxiety

Inventory (STAl)

Spielberger (1968) [64]

To assess psychological distress in medically ill patients. The original HADS was modified with removal of question 11 of the original HADS

"I feel restless as if I have to be on the move".

40 To assess trait and state anxiety.

STAls: 20 items assess trait anxiety. STAls is defined as an unpleasant emotional arousa in face of threatening demands or dangers; STAlt: 20 items assess state anxiety. STAlt reflects the existence of stable individual differences in the tendency to respond with state anxiety

in the anticipation of treating situations.

These two parts differ in the item wording

in the response format (intensity versus

frequency), and in the instructions given

for responses.

Depression Beck Depression Inventory (BDI) Beck (1961) [53]

To assess severity of depressive symptoms.

Hamilton rating scale for depression (HAM-D) Hamilton (1960) [63]

To assess patient's level of depression.

The first 17 of the 21 items contribute to the total score and items 18-21 give additional information, not part of the scale, such as paranoia and diurnal variation

4-point scale. Total scores for anxiety

range from 0 to 21

$\leq 7$ : non-cases

8-10: possible clinical levels of distress

11-21: clinical levels of distress

4-point scale. Total scores for anxiety

range from 0 to 18 .

Score interpretation:

Scores of 9-18: case level anxiety

4-point scale. Total scores for anxiety

(STAls and STAlt) range from 20 to 80.

Score interpretation:

20-39: low anxiety

40-59: medium anxiety

60-80: high anxiety

4-point scale. Total scores for depression range from 0 to 63.

$0-9$ : no depressive symptoms

10-18: mild to moderate depressive symptoms

19-29: moderate to severe depression

3: severe depression

8 items 5-point scale; 9 items 3-point scale.

Total scores for depression range from 0 to 50 .

Generic

Score interpretation:

$8-13=$ mild depression

14-18 = moderate depression

19-22 $=$ severe depression

$23-50=$ very severe depression

$\begin{array}{lll}\text { Hospital Anxiety and Depression Scale } & 7 & \text { To assess psychological distress in medically ill } \\ \text { subscale depression (HADS-d) } & \text { patients. The instrument concentrates on the }\end{array}$ subscale depression (HADS-d) patients. The instrument concentrates on the
psychic rather than the somatic symptoms

psychic rather than the somatic symptoms

an assessment of mood independent

4 -point scale. Total scores for depression

Generic

range from 0 to 21 .

11-21: clinical levels of distress 
Table 2 Psychological factor measurements (Continued)

of levels of physical disability in patients

with medical illnesses.

Hospital Anxiety and Depression scale subscale depression

(HADS-d) - modified version 2

Abrahams (1997) [66]

Hospital Anxiety and Depression

Scale subscale depression

(HADS-d) - modified version 1

Gibbons (2011) [56]

Depressive disorders: DSM-IV. American Psychiatric Association (2000) [67]

ALS-Depression-Inventory (ADI-12) Kubler (2005) [34]

To assess depressive symptoms, specifically developed for ALS patients and addresses depressive symptoms excluding increasing physical impairments commensurate with ALS.

Zung Depression Scale (ZDS) Zung (1965) [68] also called

Zung Self-Rating Depression Scale (SDS) (1965)

To assess six states of mood: tension-anxiety, depression-dejection, anger-hostility, vigouractivity, fatique-inertia, and confusion-bewilderment.

Religiosity

Idler Index of Religiosity (IRR) Idler (1987) [70]

To assess the level of religiosity. It addresses both public and private aspects of religiosity: Public religiosity (IIR-Pu) (2 items): frequency of church attendance and number of church member known personally

Private religiosity (IIR-Pr) (2 items) how religious they perceived themselves to be and the amount of strength and comfort obtained from religious practices. 4-point scale. Total scores for depression range from 0 to 18 .

Score interpretation:

$\leq 7$ : non-cases

8-10: possible clinical levels of distress

11-21: clinical levels of distress

4-point scale. Total scores for depression

range from 0 to 16 ( $T$ wo items in the

depression subscale were recorded 0-1-1-2).

Score interpretation:

Scores of 8-16: case level depression.

Score interpretation:

5 out of 9 symptoms have to be present and

represent a change from previous functionin

at least one of the symptoms is either (1)

depressed mood or (2) loss of interest or pleasure.

4-point scale. Total scores for depression

range from 12 to 48 .

$<22$ : absence of depression

22-28: mild depression

22-28. mild depressio

4-point scale. Total scores for depression

range from 20 to 80

Score interpretation:

60-69: moderate depression

70-80: severe depression

Abbreviated 37-item version of the original scal using the 5-point Likert Scale; 0 (not at all) to 4 (extremely). Total mood disturbance (TMD): sum

of the subscales.

Score interpretation:

Higher scores reflect higher presence of the

mood state.

Public religiousness: 1-item, 6-point scale; 1-item,

4-point scale

Private religiousness: 1-item, 4- point scale; 1-item,

3 -point scale

The religiosity scores are summed to produce public private, and total religiosity; scores range from 2-10, $2-7$ and $4-17$, respectively.

Score interpretation:

Higher scores indicate higher level of religiosity.

6-point scale. Total scores of spiritual well-being

range from 6 to 36 .

Score interpretation:

Higher scores indicate higher spiritual well-being. 
Table 2 Psychological factor measurements (Continued)

\begin{tabular}{|c|c|c|c|c|c|c|}
\hline & $\begin{array}{l}\text { Spiritual Well-being Scale (SWBS) (2) } \\
\text { Ellison (1983) [72] }\end{array}$ & 20 & $\begin{array}{l}\text { The scale consists of } 10 \text { religious well-being items } \\
\text { (RWB) and } 10 \text { existential well-being items (EWB); } \\
\text { spiritual well-being. }\end{array}$ & $\begin{array}{l}\text { 6-point scale. Total scores (RWB + EWB) of spiritual } \\
\text { well-being range from } 20 \text { to } 120 \text {. } \\
\text { Score interpretation: } \\
\text { Higher scores indicate higher spiritual well-being. }\end{array}$ & Generic & {$[47]$} \\
\hline Mindfulness & $\begin{array}{l}\text { Langer mindfulness scale (LMS) } \\
\text { Pirson (2012) [73] }\end{array}$ & 14 & $\begin{array}{l}\text { Three domains associated with mindful thinking: } \\
\text { novelty seeking, engagement and novelty producing. }\end{array}$ & $\begin{array}{l}\text { Total scores range from } 14-98, \\
\text { Score interpretation: } \\
\text { Higher scores reflect higher mindfulness }\end{array}$ & Generic & [29] \\
\hline Hopelessness & $\begin{array}{l}\text { Becks Hopelessness Scale (BHS) } \\
\text { Beck (1974) [74] }\end{array}$ & 20 & $\begin{array}{l}\text { To assess three major aspects of hopelessness: feelings } \\
\text { about the future, loss of motivation, and expectations. }\end{array}$ & $\begin{array}{l}\text { 2-point scale. Total scores of hopelessness } \\
\text { range from } 0 \text { to } 20 \text {. } \\
\text { 8-13: moderate hopelessness } \\
\text { >14: severe hopelessness } \\
\text { Score interpretation: } \\
\text { Higher scores reflect higher levels of } \\
\text { hopelessness. }\end{array}$ & Generic & [45] \\
\hline $\begin{array}{l}\text { Perception of burden } \\
\text { to others }\end{array}$ & $\begin{array}{l}\text { Zarit Burden Inventory (ZBI) - revised } \\
\text { Zarit (1980) [75] }\end{array}$ & 3 & $\begin{array}{l}\text { Three items of the original ZBI were revised to measure } \\
\text { patient beliefs that their medical condition stressed, } \\
\text { burdened, or caused financial hardship to their family. }\end{array}$ & $\begin{array}{l}\text { 5-point scale. Total score of perception } \\
\text { of burden to others ( } 1 \text { item) range } \\
\text { from } 0 \text { to } 4 \text {. } \\
\text { Score interpretation: } \\
\text { Higher score indicates higher perception } \\
\text { of burden to their family. }\end{array}$ & ALS & {$[45]$} \\
\hline Cognitive appraisal & $\begin{array}{l}\text { Appraisal scale } \\
\text { Smith (1993) [76] }\end{array}$ & 4 & $\begin{array}{l}\text { To assess patients' primary (motivational relevance, } \\
\text { motivational congruence) and secondary appraisal } \\
\text { (problem-focused and emotion-focused coping potential) }\end{array}$ & $\begin{array}{l}\text { 9-point scale. Scores per item range } \\
\text { from } 1 \text { to } 9 \text {. } \\
\text { Total scores are not mentioned. } \\
\text { Score interpretation: } \\
\text { The larger the difference between the } \\
\text { two items of primary appraisal (motivational } \\
\text { relevance and motivational congruence), the } \\
\text { more patients feel threatened by the disease. }\end{array}$ & Generic & {$[30,36]$} \\
\hline \multirow[t]{3}{*}{ Coping } & $\begin{array}{l}\text { Motor Neuron Disease Coping Scale } \\
\text { (MNDCS) - adapted version } 1 \\
\text { Lee (2001) [35] }\end{array}$ & 18 & $\begin{array}{l}\text { To assess extent to which patients relied on the } \\
\text { coping strategies. } \\
18 \text { questions of the original 22-item scale were } \\
\text { assigned to } 6 \text { subscales. }\end{array}$ & $\begin{array}{l}\text { 6-point scale. Total score for each type of } \\
\text { coping was obtained by generating the } \\
\text { mean score of the grouped } \\
\text { scales. Ranges of total scores are not mentioned. } \\
\text { Score interpretation: } \\
\text { Higher score reflects greater use of the coping } \\
\text { strategy. }\end{array}$ & ALS & {$[30,36]$} \\
\hline & $\begin{array}{l}\text { Motor Neuron Disease Coping Scale } \\
\text { (MNDCS/Cope-MND)—adapted version } 2 \\
\text { Lee (2001) [35] }\end{array}$ & 9 & $\begin{array}{l}\text { To assess extent to which patients relied on the } \\
\text { coping strategies. } \\
\text { The original MNDCS was reduced to a 9-item scale. }\end{array}$ & $\begin{array}{l}\text { 6-point scale. Ranges of total scores are not } \\
\text { mentioned. } \\
\text { Score interpretation: } \\
\text { Higher scores reflect greater use of the coping } \\
\text { strategy. }\end{array}$ & ALS & [37] \\
\hline & $\begin{array}{l}\text { The Brief COPE } \\
\text { Carver (1997) [77] }\end{array}$ & 28 & $\begin{array}{l}\text { Measures } 14 \text { dimensions of coping: distraction; active } \\
\text { coping; denial; emotional support; instrumental support; } \\
\text { disengagement; venting; positive reframing; planning; } \\
\text { acceptance; humour; religion; self-blame; substance use. } \\
\text { Each dimension consists of } 2 \text { items. }\end{array}$ & $\begin{array}{l}\text { 4-point scale. No overall score. Score range per } \\
\text { dimension ranges from } 2 \text { to } 8 \text {, per item from } \\
1 \text { to } 4 \text {. } \\
\text { Score interpretation: } \\
\text { Higher score reflects greater use of the coping } \\
\text { strategy. }\end{array}$ & Generic & [46] \\
\hline Personality traits & $\begin{array}{l}\text { NEO Five Factor Inventory (NEO-FFI) } \\
\text { Costa (1992) [78] }\end{array}$ & 60 & $\begin{array}{l}\text { To assess the five dimensions of personality, postulated } \\
\text { by the five-factor model of personality: neuroticism, } \\
\text { extraversion, openness, agreeableness, and conscientiousness. }\end{array}$ & $\begin{array}{l}\text { 5-point scale. Each of the five-factor subscales } \\
\text { consists of } 12 \text { items, resulting in mean factor } \\
\text { scores ranging from } 0 \text { to } 4 . \\
\text { Score interpretation: } \\
\text { Higher score reflects a type of personality. }\end{array}$ & Generic & [27] \\
\hline
\end{tabular}


Table 3 Global Quality of Life measurements

\begin{tabular}{|c|c|c|c|}
\hline $\begin{array}{l}\text { Global QoL Measurement } \\
\text { and reference }\end{array}$ & $\begin{array}{l}\text { Number } \\
\text { of items }\end{array}$ & Description & $\begin{array}{l}\text { References in } \\
\text { this review }\end{array}$ \\
\hline $\begin{array}{l}\text { The Schedule for the Evaluation of } \\
\text { Quality of Life (SEIQoL) } \\
\text { McGee (1991) [79] } \\
\text { O'Boyle (1992) [80] }\end{array}$ & 46 & $\begin{array}{l}\text { SEIQOL assesses overall subjective QoL as judged by the patient in healthy } \\
\text { or ill individuals. It is derived from a decision analysis technique known as } \\
\text { judgement analysis, administered through a semi-structured interview. Patients } \\
\text { rate their satisfaction with areas of their life by assessing three aspects of QoL. } \\
\text { The patients have to 1) nominate the life areas (cues) which are important to } \\
\text { their QoL; 2) rate their current level of functioning in each of these salient areas; } \\
\text { and 3) rate the relative importance of each of their chosen cues. } \\
\text { SEIQoL index score: the SEIQoL scores are entirely person-specific, for the } \\
\text { purpose of group analyses an overall global or index QoL score (also referred } \\
\text { to as a total QoL score) is calculated. The resulting SEIQoL index ranges from } 0 \\
\text { (worst possible QoL) to } 100 \text { (best possible QoL). }\end{array}$ & {$[15,42]$} \\
\hline
\end{tabular}

The Schedule for the evaluation of Quality of Life-Direct Weighting (SEIQoL-DW) Hickey (1996) [81]

The McGill Quality of Life Questionnaire (MQOL)

Cohen SR (1995/1996) [82, 83]

QoL-single-item question

Self-developed by Ganzini (1999) [45]

QoL-single-item question

Self-developed by Krampe (2008) [27]
SEIQoL-DW is a shorter, direct-weight (DW) version of the SEIQoL, employs an alternative method of deriving cue weights using a colored disk. SEIOoL-DW index score: The SEIOoL-DW scores are entirely person-specific: for the purpose of group analyses an overall global or index QoL score (also referred to as a total QoL score) is calculated. The resulting SEIQoL index ranges from 0 (worst possible QoL) to 100 (best possible QoL).

MQOL assesses overall subjective QoL as judged by the patient. Subjects evaluate their lives over the past 2 days on five subscales using a 10-point semantic-differential format. Originally designed for cancer and HIV patients. It is not heavily weighted toward physical function and it includes an existential element.

MQOL includes five domains, two of which are health-related: Physical Symptoms (MQOL-Ph) (3 items) and Physical Well-being (MQOL-PW) (1 item); and three are non-health related: Psychological symptoms (MQOL-Ps) (4 item); Existential Well-being (MQOL-EW) (6 items) and Social Support (MQOL-Su) (2 items). Scores on the subscales range from 0 (worst) to 10 (best). The MQOL total score is the mean of the 5 subscales, score ranges from 0 (worst QoL) to 10 (best QoL). MQOL-SIS: besides the subscales there is also a Single-ltem Score (SIS): the patient is asked to indicate his/her self-perceived overall QoL in the past two days in a single-item scale (SIS) measuring overall subjective QoL, rated from 0 (very bad) to 10 (excellent). significant relationships with HRQoL; anxiety was strongly $(-0.53)$ negatively associated with HRQoL. A similar contribution was obtained from multivariate analyses [19]. In contrast, one high quality study failed to find any relationship between anxiety and HRQoL [40].

Significant negative associations with global QoL were found in one out of three studies [41]. More specifically, low trait and state anxiety was associated with higher global QoL and was found in the diagnostic as well as the follow-up phase [41]. Two studies, of which one used a modified HADS, did not find any significant associations with global QoL $[15,19]$.

\section{Depression}

In total, fourteen studies assessed depression in relation to QoL [10, 13, 15, 19, 27, 28, 37, 38, 40-45]. Eight studies reported associations with HRQoL and eight studies with global QoL. Two studies reported both HRQoL and global QoL outcomes.

A significantly negative association with depression and HRQoL was reported in seven out of eight studies, including two of high quality, of which one used a modified HADS. Depression was moderately to strongly $(-0.430 ;-0.60 ;-0.617)[10,37,42]$ correlated with HRQoL [10, 27, 42-44]. The contribution of depressive symptoms to HRQoL was also endorsed in regression analysis [19, 27, 37, 43, 44]. A single study of high quality failed, however, to find a significant association with depression and HRQoL in bivariate correlations [40]. Another study used four different HRQoL measures and found two out of four significant associations between depression and HRQoL in bivariate and multivariate analysis [44].

A significantly negative association with depression and Global QoL was reported in four out of eight 
Table 4 Health-related Quality of Life measurements

\begin{tabular}{|c|c|c|c|}
\hline $\begin{array}{l}\text { Health-related QoL } \\
\text { Measurement and reference }\end{array}$ & $\begin{array}{l}\text { Number } \\
\text { of items }\end{array}$ & Description & $\begin{array}{l}\text { References in } \\
\text { this review }\end{array}$ \\
\hline $\begin{array}{l}\text { The 36-items Short Form of the } \\
\text { Medical Outcomes Study } \\
\text { questionnaire (SF-36) } \\
\text { Ware (1993) [52] }\end{array}$ & 36 & $\begin{array}{l}\text { SF-36 is a standardised, generic health-related quality of life measure. It consists } \\
\text { of } 36 \text { items covering } 8 \text { dimensions. Each dimension is transformed into a 0-100 } \\
\text { scale on the assumption that each question carries equal weight. High scores } \\
\text { indicate good QoL. Four of these dimensions (limitations in physical functioning } \\
\text { (PF); role limitations due to physical health problems (RP), bodily pain (BP), and } \\
\text { general health perceptions (GH)) are summarized in the Physical Component } \\
\text { Score (PCS), and four others (vitality (VT); social functioning (SF), role limitations } \\
\text { due to emotional problems (ER), general mental health (MH)), in the Mental } \\
\text { Component Score (MCS). }\end{array}$ & {$[40,44,46]$} \\
\hline $\begin{array}{l}\text { Sickness Impact Profile (SIP) } \\
\text { Bergner (1981) [84] }\end{array}$ & 136 & $\begin{array}{l}\text { SIP measures physical, mental and social aspects of health-related functioning; } \\
\text { it contains statements regarding behaviour "sickness impact" and the individual } \\
\text { is asked to respond by checking items that describe their health status. SIP contains } \\
136 \text { items in } 12 \text { categories and two dimensions (physical and psychosocial). Overall, } \\
\text { category and dimension scores may be calculated from 0-100 (best). }\end{array}$ & [47] \\
\hline $\begin{array}{l}\text { Sickness Impact Profile (SIP/ALS-19) } \\
\text { McQuire (1997) [39] }\end{array}$ & 19 & $\begin{array}{l}\text { SIP/ALS-19 assess health-related QoL. It is a questionnaire consisting of } 19 \text { items } \\
\text { from the full SIP (Sickness Impact Profile) believed to have the greatest impact on } \\
\text { QoL, based on opinions of ALS clinical specialists. Extracted from the full SIP total } \\
\text { score range from 0-100 (best). }\end{array}$ & {$[14,31]$} \\
\hline $\begin{array}{l}\text { EuroQoL-5D } \\
\text { Brazier (1993) [85] }\end{array}$ & 5 & $\begin{array}{l}\text { EuroQoL-5D assess health-related QoL. It consists of five questions that relate to } \\
\text { five dimensions of health: mobility, self-care. usual activities, pain/discomfort, } \\
\text { anxiety/depression. Each dimension is divided into three levels of severity ( } 1 \text {, } \\
\text { no problem; } 3 \text { severe problem). The EQ-5D-index score can be calculated. }\end{array}$ & {$[10,44]$} \\
\hline $\begin{array}{l}\text { EQ VAS } \\
\text { Konig (2005) [86] }\end{array}$ & 1 & $\begin{array}{l}\text { EQ VAS assess health-related QoL. It is a visual analogue scale (VAS thermometer } \\
\text { type) to rate patients current HRQoL ranging from } 0 \text { (worse imaginable health state) } \\
\text { to } 100 \text { (best imaginable health state). }\end{array}$ & [44] \\
\hline $\begin{array}{l}\text { World Health Organization } \\
\text { Quality of Life brief questionnaire } \\
\text { (WHOQoL-BREF) } \\
\text { Skevington (2004) [87] }\end{array}$ & 26 & $\begin{array}{l}\text { WHOQOL-BREF assesses quality of life within the context of an individual's culture, } \\
\text { value systems, personal goals, standards and concerns. Generic instrument, measures } \\
\text { QoL of life across } 4 \text { domains: physical health ( } 7 \text { items), psychological health ( } 6 \text { items), } \\
\text { social relationships ( } 3 \text { items) and environment ( } 8 \text { items). Domain scores can be } \\
\text { transformed to total scores from } 0 \text { (worse imaginable health state) to } 100 \text { (best } \\
\text { imaginable health state). Two other items measure overall QoL and general health. } \\
\text { Items are rated on a 5-point scale (low score of } 1 \text { to high score of 5) to determine } \\
\text { a raw item score. Subsequently, the mean score for each domain is calculated, resulting } \\
\text { in a mean score per domain that is between } 4 \text { and } 20 \text {. Finally, this mean domain score } \\
\text { is then multiplied by } 4 \text { in order to transform the domain score into a scaled score, with } \\
\text { a higher score indicating a higher QoL. }\end{array}$ & {$[19,37]$} \\
\hline $\begin{array}{l}\text { Quality of Life Index (QL-Index) } \\
\text { Spitzer } 1981 \text { [88] }\end{array}$ & 5 & $\begin{array}{l}\text { The Spitzer Qol Index (SQLI/ QLI/ QL-Index) assesses health-related QoL in palliative } \\
\text { care populations. It covers five dimensions of quality of life: activity, daily living, health, } \\
\text { support of family and friends, and outlook on life. Each dimension is rated on a } \\
\text { three-point Likert scale (0 to 2), with the range of scores from } 0 \text { to 10. Lower scores } \\
\text { reflect a higher QoL. }\end{array}$ & [43] \\
\hline
\end{tabular}

studies, in both bivariate and multivariate analysis $[13,27,28,41]$. Depression was moderately $(-0.36)$ [28] negatively associated with global QoL. In four other studies, however, including 2 which used ALSspecific questionnaires, no significant correlations between depression and global QoL were demonstrated $[15,38,42,45]$.

A prospective long-term follow-up study reported the relationship between depression and HRQoL and global QoL during the first year after baseline measurement. Patients who were more depressed had lower HRQoL and global QoL scores at month 1 and during a 12month follow-up. The results of a linear mixed model analysis showed no interaction effect between depression and time, indicating that more depressed patients did not differ from less depressed patients as far as the trajectories of Global QoL and HRQoL were concerned [27].

\section{Confusion-bewilderment}

One study examined the relation between 'confusion-bewilderment' and QoL. In regression analysis, this mood state made a significant positive contribution to HRQoL $(\beta=0.33)$ [19].

\section{Beliefs associated with QoL}

With regard to beliefs, relationships between QoL and religiosity, spirituality, mindfulness, coping, hopelessness, perception of burden and cognitive appraisal were found. 
Table 5 Methodological quality assessment

\begin{tabular}{|c|c|c|c|c|c|c|c|c|c|c|}
\hline Reference & Year & $\begin{array}{l}\text { Internal } \\
\text { validity }\end{array}$ & $\begin{array}{l}\text { Control of } \\
\text { drop out }\end{array}$ & $\begin{array}{l}\text { External } \\
\text { validity }\end{array}$ & $\begin{array}{l}\text { Statistical } \\
\text { validity }\end{array}$ & $\begin{array}{l}\text { Proportion } \\
\text { Sample size } \\
\text { vs determinants }\end{array}$ & Multi-collinearity & $\begin{array}{l}\text { Confounding } \\
\text { bias }\end{array}$ & Reporting & $\begin{array}{l}\text { Total } \\
\text { (max } 8 \text { points) }\end{array}$ \\
\hline Bremer [16] & 2004 & 1 & 1 & 1 & 1 & 0 & 0 & 0 & 1 & 5.0 \\
\hline Chio [13] & 2004 & 1 & 0.5 & 1 & 1 & 0 & 0 & 1 & 1 & 5.5 \\
\hline Clarke [15] & 2001 & 1 & 1 & 1 & 1 & 0 & 0 & 0 & 1 & 5.0 \\
\hline Dal-Bello-Haas [47] & 2000 & 1 & 0 & 0.5 & 1 & 0 & 0 & 0 & 1 & 3.5 \\
\hline Ganzini [45] & 1999 & 0 & 1 & 0.5 & 1 & 1 & 0 & 1 & 1 & 5.5 \\
\hline Gibbons [37] & 2013 & 1 & 0 & 1 & 1 & 1 & 1 & 1 & 1 & 7.0 \\
\hline Goldstein [38] & 2002 & 1 & 0 & 1 & 1 & 0 & 0 & 0 & 0 & 3.0 \\
\hline Ilse [10] & 2015 & 1 & 0 & 1 & 1 & 0 & 0 & 0 & 1 & 4.0 \\
\hline Krampe [27] & 2008 & 0 & 0 & 1 & 1 & 0 & 0 & 1 & 1 & 4.0 \\
\hline Lule [28] & 2008 & 1 & 0 & 0.5 & 1 & 0 & 0 & 1 & 1 & 4.5 \\
\hline Matuz [36] & 2010 & 1 & 0 & 1 & 1 & 0 & 1 & 1 & 1 & 6.0 \\
\hline Matuz [30] & 2015 & 1 & 1 & 1 & 1 & 0 & 0 & 1 & 1 & 6.0 \\
\hline McCabe [19] & 2009 & 1 & 0 & 0.5 & 1 & 1 & 0 & 1 & 1 & 5.5 \\
\hline Montel [46] & 2012 & 1 & 0 & 1 & 1 & 0 & 0 & 0 & 1 & 4.0 \\
\hline Pagnini [29] & 2015 & 1 & 0.5 & 0.5 & 1 & 1 & 0 & 1 & 1 & 6.5 \\
\hline Peric [40] & 2010 & 1 & 0.5 & 1 & 1 & 0 & 1 & 1 & 1 & 6.5 \\
\hline Pizzimenti [43] & 2013 & 1 & 1 & 1 & 1 & 1 & 1 & 1 & 1 & 8.0 \\
\hline Robbins [31] & 2001 & 1 & 0.5 & 0.5 & 1 & 1 & 0 & 1 & 1 & 6.0 \\
\hline Simmons [14] & 2000 & 1 & 0.5 & 1 & 1 & 0 & 0 & 0 & 1 & 4.5 \\
\hline Tramtoni [42] & 2012 & 1 & 0 & 0.5 & 1 & 0 & 0 & 1 & 1 & 4.5 \\
\hline Vignola [41] & 2008 & 1 & 0.5 & 1 & 1 & 0 & 0 & 1 & 1 & 5.5 \\
\hline Winter [44] & 2010 & 1 & 0.5 & 0.5 & 1 & 0 & 0 & 1 & 1 & 5.0 \\
\hline
\end{tabular}

Note. 1 = internal validity: use of validated and reliable measures, 2 = control of patient drop-out: including nonresponse analysis and describing executive patients, $3=$ external validity: specifying in/exclusion criteria and demographic and disease characteristics (diagnosis, age, gender, site of ALS onset, time since diagnosis, severity), $4=$ statistical validity: testing for statistical significance, $5=$ adequate sample size in relation to the number of determinants (univariate ratio $20: 1$ and multivariate ratio 10:1), $6=$ control for multicollinearity, $7=$ control for potential confounding variables, $8=$ clear description of main finding [17]

\section{Religiosity}

Five studies assessed the relationship between religiosity and QoL [13, 14, 16, 31, 46]: three of these reported HRQoL, four global QoL and two studies both HRQoL and global QoL outcomes.

Two out of three studies did not find any significant relationships between religiosity and HRQoL [14, 46]. Regression analyses of a third study, which was of high quality, [31] revealed that a high level of religiosity made a significant positive contribution to HRQoL at 6 months' follow-up, but not at the earlier assessment (3 months' follow-up).

Three out of four studies [13, 14, 16] showed that a higher level of religiosity was significantly related to higher global QoL. Both 'religiosity' and 'private religiosity' (how religious patients perceived themselves to be and the amount of strength and comfort obtained from religious practices) developed a significant, moderate to strong association with global QoL over time (3-16 months' and 6-16 months' follow-up, respectively) [16]. Regression analysis confirmed this increasing relationship between 'private religiosity' and global QoL with time and showed an increase in explained variance of $16 \%$ at 12 months' follow-up [16]. On the other hand, one high quality study did not find any significant associations with religiosity and global QoL at 3 or 6 months' follow-up [31].

\section{Spirituality}

Two studies tested the correlation between spirituality and QoL [16, 47]. One used an HRQoL measure [47], whereas the other a global QoL measure [16].

The first study [47] split spiritual well-being along the dimensions of religious well-being (which refers to a relationship with God or what is understood as a spiritual being) and existential well-being (which involves a sense of purpose and meaning in life as a means of feeling connected to the world, separate from any specifically religious reference, beliefs and needs). Existential well-being was not associated with HRQoL. In contrast, religious well-being was strongly associated (-0.99) with higher HRQoL, independent of the clinical phase of ALS. 
Table 6 Results of the bivariate and multivariate associations between psychological factors and QoL in patients with ALS

\begin{tabular}{|c|c|c|c|c|c|c|c|c|c|}
\hline & Psychological Factor & Measure Psychological factor & & Measure QoL & $\begin{array}{l}\text { Time-points of } \\
\text { assessment/F.U./ } \\
\text { trajectory }\end{array}$ & $\begin{array}{l}\text { Bivariate } \\
\text { Association } \\
r\end{array}$ & $\begin{array}{l}\text { Multivariate } \\
\text { Association } \\
\beta / R^{2}\end{array}$ & Ref. & $\begin{array}{l}\text { Qualit) } \\
\text { Score } \\
\text { (max. }\end{array}$ \\
\hline \multirow[t]{31}{*}{ MOOD } & Anxiety & & & & & & & & \\
\hline & Anxiety & HAM-A & HRQoL & SF-36 total & & $\mathrm{ns} / \mathrm{nr}$ & & {$[40]$} & 6.5 \\
\hline & & HAM-A & & SF-36 PCS & & $\mathrm{ns} / \mathrm{nr}$ & & & \\
\hline & & HAM-A & & SF-36 MCS & & $\mathrm{ns} / \mathrm{nr}$ & & & \\
\hline & & HADS-a ${ }^{1}$ & & WHOQoL-BREF total & & $-0.53^{* *}$ & & {$[37]$} & 7.0 \\
\hline & Anxiety - Tension & POMS & & WHOQoL-BREF total & & $\mathrm{nr}$ & $\beta=-0.47^{*}$ & [19] & 5.5 \\
\hline & Anxiety & HADS-a & Global QoL & SEIQoL index score & & $\mathrm{ns} / \mathrm{nr}$ & & [15] & 5.0 \\
\hline & & HADS-a & & SEIQoL-DW index score & & $\mathrm{ns} / \mathrm{nr}$ & & [38] & 3.0 \\
\hline & State anxiety & STAls $^{\circ}$ & & MQOL total & & $\mathrm{nr}$ & $\mathrm{s}^{* *} / \mathrm{nr}$ & [41] & 5.5 \\
\hline & & STAls & & MQOL total & $<1$ mo after $\mathrm{D}$. & $\mathrm{nr}$ & $\mathrm{s}^{* *} / \mathrm{nr}$ & & \\
\hline & & STAls & & MQOL total & $>1$ mo after $D$. & $\mathrm{nr}$ & $s^{*} / \mathrm{nr}$ & & \\
\hline & Trait anxiety & STAlt & & MQOL total & $<1$ mo after $\mathrm{D}$. & $\mathrm{nr}$ & $\mathrm{s}^{* *} / \mathrm{nr}$ & & \\
\hline & & STAlt & & MQOL total & $>1$ mo after D. & $\mathrm{nr}$ & $\mathrm{s}^{*} / \mathrm{nr}$ & & \\
\hline & Depression & & & & & & & & \\
\hline & Depression—Dejection & POMS & HRQoL & WHOQoL-BREF total & & $\mathrm{nr}$ & $\beta=-0.24^{*}$ & [19] & 5.5 \\
\hline & Depression & HADS-d ${ }^{1}$ & & WHOQoL-BREF total & & $-0.60^{* *}$ & $\beta=-0.41^{*}$ & [37] & 7.0 \\
\hline & & HAM-D & & SF-36 total & & $\mathrm{ns} / \mathrm{nr}$ & & {$[40]$} & 6.5 \\
\hline & & HAM-D & & SF-36 PCS & & $\mathrm{ns} / \mathrm{nr}$ & & & \\
\hline & & HAM-D & & SF-36 MCS & & $\mathrm{ns} / \mathrm{nr}$ & & & \\
\hline & & ZDS & & SF-36 total & & $-0.617^{* *}$ & & [42] & 4.5 \\
\hline & & ZDS & & QL-Index & & $\mathrm{s}^{*} / \mathrm{nr}$ & $\beta=-0.08^{*}$ & [43] & 8.0 \\
\hline & & $\mathrm{BDI}$ & & EQ-5D index score & & $-0.430^{* *}$ & & [10] & 4.0 \\
\hline & & $\left.B D\right|^{\mathrm{A}}$ & & SF-36 MCS & & $\mathrm{nr}$ & $\beta=-0.391^{* *}$ & [44] & 5.0 \\
\hline & & $\left.B D\right|^{\mathrm{A}}$ & & SF-36 PCS & & $\mathrm{ns} / \mathrm{nr}$ & & & \\
\hline & & $\left.\mathrm{BD}\right|^{\mathrm{A}}$ & & EQ-5D index score & & $\mathrm{nr}$ & $\beta=-0.272$ & & \\
\hline & & $\mathrm{BDI}^{\mathrm{A}}$ & & EQ VAS & & $\mathrm{nr}$ & $\beta=-0.381^{*}$ & & \\
\hline & & $\mathrm{BDI}$ & & HRCS & 1 mo F.U. & $\mathrm{nr}$ & $\mathrm{s} / \mathrm{nr}$ & {$[27]$} & 4.0 \\
\hline & & $\mathrm{BDI}$ & & HRCS & 12 mo F.U. & $\mathrm{nr}$ & $\mathrm{s}^{* *} / \mathrm{nr}$ & & \\
\hline & Depression $x$ time & BDI & & HRCS & over $12 \mathrm{mo}$ & $\mathrm{nr}$ & ns & & \\
\hline & Depression & ADI-12 & Global QoL & SEIQoL index score & & $-0.36^{*}$ & & [28] & 4.5 \\
\hline & & DSM-IV & & Single-item-question ${ }^{3}$ & & $\mathrm{~ns} / \mathrm{nr}$ & $\mathrm{ns} / \mathrm{nr}$ & {$[45]$} & 5.5 \\
\hline
\end{tabular}


Table 6 Results of the bivariate and multivariate associations between psychological factors and QoL in patients with ALS (Continued)

\begin{tabular}{|c|c|c|c|c|c|c|c|c|c|}
\hline & & ZDS & & SEIQoL-DW index score & & $\mathrm{nr}$ & $\mathrm{s}^{*} / \mathrm{nr}$ & [13] & 5.5 \\
\hline & & ZDS & & MQOL Single Item Score & & $\mathrm{nr}$ & $s^{*} / \mathrm{nr}$ & & \\
\hline & & ZDS & & SEIQoL index score & & -0.205 & & [42] & 4.5 \\
\hline & & $\mathrm{ZDS}^{\circ}$ & & MQOL total & & $\mathrm{nr}$ & $\mathrm{s}^{* *} / \mathrm{nr}$ & [41] & 5.5 \\
\hline & & HADS-d & & SEIQoL index score & & $\mathrm{ns} / \mathrm{nr}$ & & [15] & 5.0 \\
\hline & & HADS- $d^{2}$ & & SEIQoL-DW index score & & $\mathrm{ns} / \mathrm{nr}$ & & [38] & 3.0 \\
\hline & & $\mathrm{BDI}$ & & Single-item-question ${ }^{4}$ & 1 mo F.U. & $\mathrm{nr}$ & $s^{*} / \mathrm{nr}$ & [27] & 4.0 \\
\hline & & $\mathrm{BDI}$ & & Single-item-question ${ }^{4}$ & 12 mo F.U. & $\mathrm{nr}$ & $s^{*} / n r$ & & \\
\hline & Depression $\mathrm{x}$ time & $\mathrm{BDI}$ & & Single item question ${ }^{4}$ & over $12 \mathrm{mo}$ & $\mathrm{nr}$ & ns & & \\
\hline & Confusion - Bewilderment & POMS & Global QoL & WHOQoL-BREF total & & $\mathrm{nr}$ & $\beta=0.33^{*}$ & [19] & 5.5 \\
\hline \multirow[t]{23}{*}{ BELIEFS } & Religiosity & & & & & & & & \\
\hline & Religiosity & IIR-tot & HRQoL & SIP/ALS-19 total & & 0.169 & & [14] & 4.5 \\
\hline & & IIR-tot & & SIP/ALS-19 total & 3 mo F.U. & $\mathrm{nr}$ & $\mathrm{ns} / \mathrm{nr}$ & {$[31]$} & 6.0 \\
\hline & & IIR-tot & & SIP/ALS-19 total & 6 mo F.U. & $\mathrm{nr}$ & $\mathrm{s}^{* * *} / \mathrm{nr}$ & & \\
\hline & Religion - coping & Brief COPE & & SF-36 PCS/SF-36 MCS & & $-0.26^{\mathrm{P}}-0.01^{\mathrm{M}}$ & & [46] & 4.0 \\
\hline & Religiosity & $\| R$-tot & Global QoL & MQOL total & & 0.15 & & [16] & 5.0 \\
\hline & & IIR-tot & & MQOL total & 3-4 mo F.U. & 0.28 & & & \\
\hline & & IIR-tot & & MQOL total & 6-8 mo F.U. & $0.37^{* *}$ & & & \\
\hline & & IIR-tot & & MQOL total & 9-12 mo F.U. & $0.33^{*}$ & & & \\
\hline & & IIR-tot & & MQOL total & 12-16 mo F.U. & $0.46^{* *}$ & & & \\
\hline & & IIR-tot & & MQOL total & 3 mo F.U. & $\mathrm{nr}$ & $\mathrm{ns} / \mathrm{nr}$ & [31] & 6.0 \\
\hline & & IIR-tot & & MQOL total & 6 mo F.U. & $\mathrm{nr}$ & $\mathrm{ns} / \mathrm{nr}$ & & \\
\hline & & IIR-tot & & MQOL total & & 0.221 & & {$[14]$} & 4.5 \\
\hline & & IIR-tot & & MQOL Single Item Score & & $0.331^{* *}$ & & & \\
\hline & Religiosity Private & $\| \mathrm{R}-\mathrm{Pr}$ & & MQOL total & & 0.13 & $\beta=0.05 ; R^{2}=0 \%$ & [16] & 5.0 \\
\hline & & $\| \mathrm{R}-\mathrm{Pr}$ & & MQOL total & 3-4 mo F.U. & $0.42^{* *}$ & $\beta=0.31^{* *}$ & & \\
\hline & & $\| \mathrm{R}-\mathrm{Pr}$ & & MQOL total & 6-8 mo F.U. & $0.49^{* *}$ & $\beta=0.35^{* *}$ & & \\
\hline & & $\| R-P r$ & & MQOL total & 9-12 mo F.U. & $0.34^{*}$ & $\beta=0.21$ & & \\
\hline & & IIR-Pr & & MQOL total & 12-16 mo F.U. & $0.50^{* *}$ & $\beta=0.41^{* * *} ; R^{2}=16 \% \%^{* *}$ & & \\
\hline & & IIR-Pr & & SEIQoL-DW index score & & $s^{*} / \mathrm{nr}$ & & [13] & 5.5 \\
\hline & Spirituality & & & & & & & [16] & 5.0 \\
\hline & Existential well-being & $S W B S^{6}-E W B$ & HRQoL & SIP total & & $\mathrm{ns} / \mathrm{nr}$ & & {$[47]$} & 3.5 \\
\hline & Religious well-being & $S W B S^{6}-R W B$ & & SIP total & & $-0.996^{* *}$ & & & \\
\hline
\end{tabular}


Table 6 Results of the bivariate and multivariate associations between psychological factors and QoL in patients with ALS (Continued)

Mindfulness

Mindfulness

Mindfulness $x$ time

Coping

Positive coping strategies

MNDCS $^{1}$

Distraction

Active coping

Denial

Emotional support

Instrumental support

Disengagement

Venting

Positive reframing

Planning

Acceptance

Humor

Self-blame

Substance use

Problem management

Problem management

Problem appraisal

Emotion management

Emotional avoidance

Emotional avoidance

Hopelessness

Perception of burden to others ZBI- revised Cognitive appraisal

Appraisal total

Appraisal scale
Global QoL

MQOL total

MQOL total

MQOL total

MQOL total

9-12 mo Fu.

Global QoL MQOL Single Item Score

MQOL Single Item Score over 4 mo

HRQOL

WHOQOL-BREF total

SF-36 PCS/SF-36 MCS

SF-36 PCS/SF-36 MCS

SF-36 PCS/SF-36 MCS

SF-36 PCS/SF-36 MCS

SF-36 PCS/SF-36 MCS

SF-36 PCS/SF-36 MCS

SF-36 PCS/SF-36 MCS

SF-36 PCS/SF-36 MCS

SF-36 PCS/SF-36 MCS

SF-36 PCS/SF-36 MCS

SF-36 PCS/SF-36 MCS

SF-36 PCS/SF-36 MCS

SF-36 PCS/SF-36 MCS

Global QoL SEIQoL index score

SEIQoL index score

SEIQoL index score

SEIQoL index score

SEIQoL index score

SEIQoL index score

Global QoL Single-item-question ${ }^{3}$

Global QoL Single-item-question ${ }^{3}$

Global QoL SElQoL index score
3-4 mo F.U.

6-8 mo F.U.

12-16 mo F.U. $\quad 0.54^{* *}$

$\mathrm{nr}$

$\beta=0.06^{* * *}$

$\beta=0.009$

[16] 5.0

$0.46^{* *}$

$\beta=0.35^{* * *}$

[37] 7.0

$0.08^{\mathrm{P}}-0.11^{\mathrm{M}}$

$-0.16^{\mathrm{P}} \quad 0.11^{\mathrm{M}}$

$-0.15^{\mathrm{P}} \quad 0.23^{\mathrm{M}}$

$0.38^{\mathrm{P} *} \quad 0.10^{\mathrm{M}}$

$-0.31^{\mathrm{P}}-0.02^{\mathrm{M}}$

$0.16^{\mathrm{P}} \quad 0.33^{\mathrm{M}}$

$-0.10^{\mathrm{P}}-0.38^{* \mathrm{M}}$

$-0.22^{\mathrm{P}} \quad 0.32^{\mathrm{M}}$

$-0.23^{\mathrm{P}} \quad 0.11^{\mathrm{M}}$

$-0.18^{\mathrm{P}} \quad 0.23^{\mathrm{M}}$

$-0.15^{\mathrm{P}} \quad 0.25^{\mathrm{M}}$

$0.11^{\mathrm{P}}-0.24^{\mathrm{M}}$

$0.26^{\mathrm{P}}-0.44^{* \mathrm{M}}$

3-6 mo F.U.

$\beta=0.44^{* *}$

$\beta=0.42^{* *}$

$\beta=0.15$

$\beta=-0.26$

$\beta=0.39^{*}$

$\beta=0.28$

$\mathrm{s}^{* *} / \mathrm{nr}$

$s^{*} / \mathrm{nr}$

[45] 5.5

[45] 5.5

n

$R^{2}=2 \%$

[36] 6.0 
Table 6 Results of the bivariate and multivariate associations between psychological factors and QoL in patients with ALS (Continued)

\begin{tabular}{|c|c|c|c|c|c|c|c|c|}
\hline & Primary appraisal & Appraisal scale & & SEIQoL index score & & $\mathrm{nr}$ & $\beta=-0.004$ & \\
\hline & Appraisal of coping potential & Appraisal scale & & SEIQoL index score & & $\mathrm{nr}$ & $\beta=0.15$ & \\
\hline \multirow[t]{8}{*}{ PERSONALITY } & Agreeableness & NEO-FFI & Global QoL & Single-item-question ${ }^{4}$ & & $\mathrm{nr}$ & $\beta=1.88^{*}$ & {$[27]$} \\
\hline & Agreeableness & NEO-FFI & HRQoL & HRCS & & $\mathrm{nr}$ & $\beta=0.69^{*}$ & \\
\hline & Agreeableness $x$ time & NEO-FFI & Global QoL & Single-item-question ${ }^{4}$ & over $12 \mathrm{mo}$ & $\mathrm{nr}$ & $\beta=-0.28^{*}$ & \\
\hline & Agreeableness $x$ time & NEO-FFI & HRQoL & HRCS & over 12 mo & $\mathrm{nr}$ & $\beta=-0.09^{*}$ & \\
\hline & Neuroticism & NEO-FFI & Global QoL & Single-item-question ${ }^{4}$ & & $\mathrm{nr}$ & $\mathrm{ns} / \mathrm{nr}$ & \\
\hline & Extraversion & NEO-FFI & & Single-item-question ${ }^{4}$ & & $\mathrm{nr}$ & $\mathrm{ns} / \mathrm{nr}$ & \\
\hline & Openness & NEO-FFI & & Single-item-question ${ }^{4}$ & & $\mathrm{nr}$ & $\mathrm{ns} / \mathrm{nr}$ & \\
\hline & Conscientiousness & NEO-FFI & & Single-item-question ${ }^{4}$ & & $\mathrm{nr}$ & $\mathrm{ns} / \mathrm{nr}$ & \\
\hline
\end{tabular}

Note. Significance levels: ${ }^{*} p<0.1 ; * * p<0.01 ; * * *<0.001$

Abbreviations: $n s$ not significant, $n r$ not reported, $r$ correlation, $\beta$ standardized regression coefficient, $R^{2}$ explained variance of the determinant, $D$ diagnosis, $A$ obtained from the author, $F . U$. follow-up, 1 modified version 1,2

modified version 2, 3 self-developed single-item-question by Ganzini, 4 self-developed single-item-question by Krampe, 5 SWBS developed by Reed [51], 6 SWBS developed by Ellison [52], HRCS health-related QoL composite

score, $P C S$ physical component summary (P), MCS mental component summary (M), TO data from baseline measurement, $O$ overall (both $<1$ month after diagnosis and $>1$ month after diagnosis); Abbreviations of measurements: see Tables 2, 3 and 4 
The second study [16] showed that spirituality (which refers to a search for the sacred or divine through any type of life experience) was strongly associated (0.54) with higher global QoL at long-term follow-up (12-16 months) but not at the earlier assessments.

\section{Mindfulness}

One recent high quality study found a positive association between mindfulness 'the process of actively making new distinctions about a situation and its environment, or its current context, rather than relying on previous categorizations from the past' [48] and global QoL [29]. The results of a linear mixed model analysis showed that high mindfulness at baseline predicted significantly higher global QoL scores after four months [29].

\section{Coping}

Four studies, including three high quality studies, investigated the associations between coping and QoL [30, 36, 37, 46], in which two studies reported HRQoL and two studies global QoL measures.

One high quality study out of two showed that 'adoption of positive coping strategies' was moderately positively (0.46) associated with HRQoL [37]. The second study [46] related 14 coping strategies to HRQoL (36-item Short Form (SF36); Mental Component Summary score (MCS) and Physical Component Summary scores (PCS)). Of these 28 bivariate correlations, three were significantly associated: negative, moderate correlations were noted between MCS and substance use $(-0.44)$ and between MCS and venting (an externalizing coping technique, the outward expression of emotions) (-0.38). PCS was positively, moderately associated with emotional support (0.38). The other 11 coping strategies (e.g. acceptance, denial, selfblame) were not associated with HRQoL [46].

Two high quality studies, analyzing the same cohort, showed that the coping strategy 'problem management' was positively associated with global QoL. The first study [36] with a cross-sectional design, using multivariate regression analysis, revealed positive associations between the coping strategy 'problem management' and 'emotional avoidance' and global QoL at baseline [30]. Analysis of a longitudinal follow-up [30] revealed that only the coping strategy 'problem management' was a significant predictor; patients who searched more frequently for information and support at baseline reported higher global QoL at 3 to 6 months' follow-up [30].

\section{Hopelessness}

One study tested the association of hopelessness and global QoL [45]. It was shown that greater hopelessness was moderately correlated with lower global QoL (0.43). This relationship was still significant in a multivariate regression analysis with control variables.

\section{Perception of burden to others}

A single study examined the 'perception of burden to others'. Having the belief of being a burden to others was moderately associated with lower global QoL (0.45). The association remained significant in the regression analyses [45].

\section{Cognitive appraisal}

A single study [36] assessed 'cognitive appraisal', which was split into patient's primary (motivational relevance, motivational congruence) and secondary appraisal (problem focused and emotional focused coping potential) and related to global QoL. Results of the regression analysis showed no associations of cognitive appraisal with global QoL. The variance of the global QoL scores could not be significantly accounted for by any of the appraisals scales.

\section{Personality associated with QoL \\ Neuroticism, extraversion, openness, agreeableness and conscientiousness}

One study [27] investigated the relationship between personality factors and QoL. In the regression analysis, it was shown that among the five personality factors (neuroticism, extraversion, openness, agreeableness and conscientiousness), only agreeableness had a strong positive association with both global QoL and HRQoL. Agreeableness refers to 'a personality trait manifesting itself in individual behavioral characteristics that are perceived as kind, sympathetic, cooperative, warm and considerate' [49]. There was also a significant interaction effect of agreeableness and time, meaning that agreeableness significantly influenced the course of global QoL and HRQoL; patients who scored higher on agreeableness had higher QoL ratings at baseline measurement but their decline in QoL was steeper compared to patients with lower scores in agreeableness [27].

\section{Discussion}

The aim of the present review was to systematically collect and appraise evidence of the relationships between psychological factors (mood, beliefs, personality) and QoL in patients with ALS. This review showed that higher levels of anxiety and depression appeared to be related to a poorer HRQoL, whereas a higher level of religiosity seemed to be related to higher global QoL. Furthermore, associations might change during the disease course.

\section{Mood}

Anxiety seemed to be negatively related to HRQoL, because higher levels of anxiety were consistently associated with a poorer HRQoL. In contrast, global QoL showed no associations with anxiety; the association could not, however, be refuted because of one poor quality study. Depression was negatively associated with HRQoL, suggesting that the presence of depressive 
symptoms is related to a poorer HRQoL. On the other hand, for global QoL, we could not support a relationship with depression, because of inconsistent results.

Mood appeared to be related to HRQoL but not to global QoL. This is in concurrence with cancer studies $[9,50]$, which also revealed that depression explained a large amount of variation in HRQoL, but not global QoL. Our results might in part be ascribed to conceptual overlap [51] between determinants and outcomes. For example, questions about feelings of anxiety and depression are often also included in a HRQoL measure (e.g. "Have you felt downhearted and blue?" SF-36; question of [52]), and so studying anxiety and depression as determinants of HRQoL may result in strong associations between determinants and outcomes. This contamination is less likely between mood and global QoL measures, because global QoL assesses such a wide spectrum of domains that contribute to overall QoL as judged by the patient.

Furthermore, it is important to be aware that there is recent evidence suggesting that depression questionnaires, specifically the Beck Depression Inventory (BDI) [53] and to a lesser degree the Hospital Anxiety and Depression Scale (HADS) [54], tend to overestimate depression in ALS, since these scores are highly influenced by the physical impairment of the patients $[55,56]$. Consequently, the relationships that have been found between depression and HRQoL is questionable.

\section{Beliefs}

There seemed to be no relationship between religiosity and HRQoL, because most studies showed weak and nonsignificant associations. However, religiosity appeared to be positively associated with global QoL in the majority of the studies, including one high quality study. Consequently, we support the assumption that a high level of religiosity made a significant positive contribution to better global QoL. However, these results might also point out to contamination in concepts between religiosity and global QoL since the The McGill Quality of Life Questionnaire (MQOL) total score includes items about existential well-being.

Religiosity might be important for the individual's global QoL because it may create meaning and coherence when an individual's world is devastated by a distressing and progressive disease [47]. These findings are mirrored in other diseases such as Multiple Sclerosis [57] and advanced cancer [58]. It should be taken into account that most of the included studies about religiosity are from North America and the religiosity questionnaire which was used relies predominantly on monotheistic terminology, about belief in God or experience of God [59]. In current (western) culture, people are more interested in spirituality [60] and mindfulness [55] and are searching for a connection with the divine within themselves, instead of a connection with an external almighty power [60]. The fact that religiosity and spirituality are culture dependent and are defined differently in each country might explain the heterogeneity in findings on association of QoL.

\section{Personality}

The search has yielded only one hit concerning personality factors, suggesting that personality factors were not considered to be the most important psychological factors influencing QoL. Only a single study of low quality was included, conclusive associations between HRQoL or global QoL could, therefore, not be established.

\section{Miscellaneous}

Several other psychological factors were reported in only a single study or measured twice in the same cohort [30, 36]: there was, therefore, insufficient evidence to support associations between HRQoL or global QoL and the following psychological factors: confusion-bewilderment (mood); spirituality, mindfulness, coping styles, hopelessness, perception of burden, cognitive appraisal (beliefs) and neuroticism, extraversion, openness, agreeableness and conscientiousness (personality).

\section{Associations throughout the disease course}

Although there was not enough evidence per psychological factor, it is valuable to point out with regard to psychological factors as a whole, that associations might change throughout the course of the disease; religiosity and spirituality appeared to become more positively associated with global QoL over time. This is in accordance with the theory of Waldron [61] who suggested that psychological adaptation to terminal illness may involve a shift in focus of determinants of QoL; in the initial stages of a progressive illness, patients may focus on physical functioning and on decreasing disability, but as the illness progresses, the importance of these issues may be replaced by a focus on the psychosocial and spiritual domains.

\section{Strengths and limitations of this systematic review}

This is the first systematic review on associations between psychological factors and QoL in patients with ALS. This review was carried out in accordance with the PRISMA guidelines (see online Additional file 1). The methodological quality of the studies and the consistency of the associations between psychological factors and HRQoL and global QoL were comprehensively appraised. A limitation, however, of our study is that only a small number of psychological factors could be compared, because most of the associations with QoL were only reported once. Besides, our review may have missed relevant papers published in non-English journals. Finally, as studies with 
significant results are more likely to be published than studies without significant results, publication bias has to be taken into account.

\section{Limitations of the literature}

First, the heterogeneity of the literature with respect to instruments for assessing psychological factors and QoL may have influenced the associations. Levels of anxiety and depression, for example, were measured using 5 and 7 different questionnaires, respectively, and moreover, with a mix of both generic and ALS-specific questionnaires, or questionnaires modified for ALS. Concerning QoL measures, 7 different HRQoL and 5 different global QoL (mostly generic) measures, were extracted. Second, in order to detect which psychological factors affect HRQoL and global QoL over the course of the disease, it is essential to cluster the data of patients according to the same disease stage (diagnostic stage, rehabilitation stage and terminal stage [62]). In fact, only one study analyzed the determinants of patients in the diagnostic phase separately [41]. Other longitudinal studies only reported changing associations of depression, coping, religiosity and personality factors after baseline measurement, without specific information about the disease stage. Other limitations concern studies with a crosssectional design and the overrepresentation of small studies, without an adequate sample size in relation to the number of determinants.

\section{Conclusions, clinical implications and further research}

Our results suggest that higher levels of anxiety and depression are related to a poorer HRQoL, whereas higher levels of religiosity appeared to be related to better global QoL. Furthermore, associations might change throughout the disease course.

Therefore it is important for health professionals to become aware of the relationships between psychological factors and QoL, as these relationships identify possible targets for interventions to improve QoL. It seems relevant for health professionals in ALS care, to focus on influencing mood and beliefs in order to improve HRQOL and global QoL. Furthermore, it is relevant to make a distinction between HRQoL and global QoL, because HRQoL is expected to decline, according to a decrease in mental and physical functioning, whereas global QoL seems more dependent on other factors, such as existential concerns.

More high quality research is needed to confirm the assumed association between anxiety, depression and religiosity and HRQoL and global QoL and to investigate how and when these factors can be targeted in ALS care. Coping, spirituality, mindfulness, hopelessness, perception of burden and agreeableness might be other promising factors that influence QoL, but warranted further investigation. More longitudinal studies in larger samples are needed because they allow causal relationships and effects of time to be identified. Furthermore, uniformity of measures for QoL and psychological factors, preferably ALS-specific, are required in order to obtain reliable, comparable data. As small sample sizes are inherent to ALS research, the answer may lie in international collaboration and data gathered by online survey.

\section{Additional files}

Additional file 1: Prisma Checklist (DOC $64 \mathrm{~kb})$

Additional file 2: PubMed Search (DOC $34 \mathrm{~kb}$ )

Funding

The authors are grateful for funding of this study from The Netherlands Organization for Health Research and Development (ZonMw) and the Prinses Beatrix Fonds.

\section{Authors' contributions}

AvG developed the systematic review protocol, conducted independent title, abstract and full text screening, the data analysis and wrote the first draft of the manuscript. EK made substantial contributions in the inclusion of articles and methodological quality scoring of the articles and participated in drafting and revising the review. CS was responsible for concept, design, independent title, abstract and full text screening, drafting and revising of the review. JV and LB have been involved in drafting the manuscript and revising it critically for important intellectual content. All authors read and approved the final manuscript.

Competing interest

The authors declare that they have no competing interests.

\section{Author details}

${ }^{1}$ Brain Center Rudolf Magnus and Center of Excellence for Rehabilitation Medicine, University Medical Center Utrecht and De Hoogstraat Rehabilitation, Utrecht, The Netherlands. ${ }^{2}$ Brain Center Rudolf Magnus, Department of Neurology, University Medical Center Utrecht, Utrecht, The Netherlands.

Received: 10 February 2016 Accepted: 7 July 2016

Published online: 20 July 2016

\section{References}

1. Pasinelli P, Brown RH. Molecular biology of amyotrophic lateral sclerosis: insights from genetics. Nat Rev Neurosci. 2006;7:710-23.

2. Andersen PM, Borasio GD, Dengler R, Hardiman O, Kollewe K, Leigh PN, Pradat PF, Silani $V$, Tomik B. EFNS task force on diagnosis and management of amyotrophic lateral sclerosis. EFNS task force on management of amyotrophic lateral sclerosis: guidelines for diagnosing and clinical care of patients and relatives. Eur J Neurol. 2005;12:921-38.

3. Strong MJ, Grace GM, Orange JB, Leeper HA, Menon RS, Aere C. A prospective study of cognitive impairment in ALS. Neurology. 1999;53:1665-70.

4. McCluskey LF, Elman LB, Martinez-Lage M, Van Deerlin V, Yuan W, Clay D, et al. Amyotrophic lateral sclerosis-plus syndrome with TAR DNA-binding protein-43 pathology. Arch Neurol. 2009;66:121-4.

5. Worms PM. The epidemiology of motor neuron diseases: a review of recent studies. J Neurol Sci. 2001;191:3-9.

6. Johnston CA, Stanton BR, Turner MR, et al. Amyotrophic lateral sclerosis in an urban setting: a population based study of inner city London. J Neurol. 2006;253:1642-3.

7. World Health Organization. WHOQOL: measuring quality of life. Geneva: World Health Organization; 1997. 
8. Burns TM, Graham CD, Rose MR, Simmons Z. Quality of life and measures of quality of life in patients with neuromuscular disorders. Muscle Nerve. 2012;46:9-25.

9. Llewellyn CD, McGurk M, Weinman J. Head and neck cancer: to what extent can psychological factors explain differences between health-related quality of life and individual quality of life? Br J Oral Maxillofac Surg. 2006;44:351-7.

10. Ilse B, Prell T, Walther M, Hartung V, Penzlin S, Tietz F, Witte O-W, Strauss B, Grosskreutz J. Relationships Between Disease Severity, Social Support and Health-Related Quality of Life in Patients with Amyotrophic Lateral Sclerosis. Soc Indic Res. 2015;3:871-82.

11. Cupp J, Simmons Z, Berg A, Felgoise SH, Walsh SM, Stephens HE. Psychological health in patients with ALS is maintained as physical function declines. Amyotroph Lateral Scler. 2011;12:290-6.

12. Sprangers MA, Schwartz CE. Integrating response shift into health-related quality of life research: a theoretical model. Soc Sci Med. 1999;48:1507-15.

13. Chio A, Gauthier A, Montuschi A, Calvo A, Di VN, Ghiglione P, et al. A cross sectional study on determinants of quality of life in ALS. J Neurol Neurosurg Psychiatry. 2004;75:1597-601.

14. Simmons Z, Bremer BA, Robbins RA, Walsh SM, Fischer S. Quality of life in ALS depends on factors other than strength and physical function. Neurology. 2000;55:388-92

15. Clarke S, Hickey A, O'Boyle C, Hardiman O. Assessing individual quality of life in amyotrophic lateral sclerosis. Qual Life Res. 2001;10:149-58.

16. Bremer BA, Simone AL, Walsh S, Simmons Z, Felgoise SH. Factors supporting quality of life over time for individuals with amyotrophic lateral sclerosis: the role of positive self-perception and religiosity. Ann Behav Med. 2004;28:119-25.

17. Van Leeuwen CM, Kraaijeveld S, Lindeman E, Post MW. Associations between psychological factors and quality of life ratings in persons with spinal cord injury: a systematic review. Spinal Cord. 2012;50:174-87.

18. Van Mierlo ML, Schröder C, van Heugten CM, Post MW, de Kort PL, VisserMeily JM. The influence of psychological factors on health-related quality of life after stroke: a systematic review. Int J Stroke. 2014;9:341-8.

19. McCabe MP, Firth L, O'Connor E. A comparison of mood and quality of life among people with progressive neurological illnesses and their caregivers. J Clin Psychol Med Settings. 2009;4:355-62.

20. Pagnini F. Psychological wellbeing and quality of life in amyotrophic lateral sclerosis: a review. Int J Psychol. 2013:48:194-205.

21. Bromberg MB. Assessing quality of life in ALS. J Clin Neuromuscul Dis. 2007:9:318-25

22. McLeod JE, Clarke DM. A review of psychosocial aspects of motor neurone disease. J Neurol Sci. 2007;258:4-10.

23. Cohen J. Statistical power analysis for the behavioural sciences. 2 nd ed. UK: Lawrence Erlbaum Associates; 1988.

24. World Health Organization. International Classification of Functioning, Disability and Health: ICF. Geneva: World Health Organization; 2001.

25. Ryckman R. Theories of Personality. 7th ed. Thomson/Wadsworth: Belmont; 2000.

26. Walsh SM, Bremer BA, Felgoise SH, Simmons Z. Religiousness is related to quality of life in patients with ALS. Neurology. 2003;60:1527-9.

27. Krampe H, Bartels C, Victorson D, Enders CK, Beaumont J, Cella D, et al. The influence of personality factors on disease progression and healthrelated quality of life in people with ALS. Amyotroph Lateral Scler. 2008;9:99-107.

28. Lule D, Hacker S, Ludolph A, Birbaumer N, Kubler A. Depression and quality of life in patients with amyotrophic lateral sclerosis. Dtsch Arztebl Int. 2008;105:397-403.

29. Pagnini F, Phillips D, Bosma CM, Reece A, Langer E. Mindfulness, physical impairment and psychological well-being in people with amyotrophic lateral sclerosis. Psychol Health. 2015;30:503-17.

30. Matuz T, Birbaumer N, Hautzinger M, Kübler A. Psychosocial adjustment to ALS: a longitudinal study. Front Psychol. 2015;6:1197.

31. Robbins RA, Simmons Z, Bremer BA, Walsh SM, Fischer S. Quality of life in ALS is maintained as physical function declines. Neurology. 2001;56:442-4.

32. Testa D, Lovati R, Ferrarini M, Salmoiraghi F, Filippini G. Survival of 793 patients with amyotrophic lateral sclerosis diagnosed over a 28-year period. Amyotroph Lateral Scler Other Motor Neuron Disord. 2004:5:208-12.

33. Logroscino G, Traynor BJ, Hardiman O, Chiò A, Mitchell D, Swingler RJ, Millul A, Benn E, Beghi E, EURALS. Incidence of amyotrophic lateral sclerosis in Europe. J Neurol Neurosurg Psychiatry. 2010;81:385-90.
34. Kubler A, Winter S, Ludolph AC, Hautzinger M, Birbaumer N. Severity of depressive symptoms and quality of life in patients with amyotrophic latera sclerosis. Neurorehabil Neural Repair. 2005;19:182-93.

35. Lee JN, Rigby SA, Burchardt F, Thornton EW, Dougan C, Young CA. Quality of life issues in motor neurone disease: the development and validation of a coping strategies questionnaire, the MND Coping Scale. J Neurol Sci. 2001;191:79-85.

36. Matuz T, Birbaumer N, Hautzinger M, Kubler A. Coping with amyotrophic lateral sclerosis: an integrative view. J Neurol Neurosurg Psychiatry. 2010;81:893-8.

37. Gibbons C, Thornton E, Ealing J, Shaw P, Talbot K, Tennant A, et al. The impact of fatigue and psychosocial variables on quality of life for patients with motor neuron disease. Amyotroph Lateral Scler Frontotemporal Degener. 2013;14:537-45.

38. Goldstein LH, Atkins L, Leigh PN. Correlates of Quality of Life in people with motor neuron disease (MND). Amyotroph Lateral Scler Other Motor Neuron Disord. 2002;3:123-9.

39. McGuire D, Garrison L, Armon C, Barohn RJ, Bryan WW, Miller R, et al. A brief quality-of-life measure for ALS clinical trials based on a subset of items from the sickness impact profile. The Syntex-Synergen ALS/CNTF Study Group. J Neurol Sci. 1997;152:S18-22.

40. Peric' S, Rakocevic-Stojanovic V, Stevic Z, Basta I, Pavlovic S, Vujanac V, et al. Health-related quality of life in patients with myotonic dystrophy type 1 and amyotrophic lateral sclerosis. Acta Neurol Belg. 2010;110:71-7.

41. Vignola A, Guzzo A, Calvo A, Moglia C, Pessia A, Cavallo E, et al. Anxiety undermines quality of life in ALS patients and caregivers. Eur J Neurol. 2008; 15:1231-6.

42. Tramonti F, Bongioanni P, Di BC, Davitti S, Rossi B. Quality of life of patients with amyotrophic lateral sclerosis. Psychol Health Med. 2012;17:621-8.

43. Pizzimenti A, Aragona M, Onesti E, Inghilleri M. Depression, pain and quality of life in patients with amyotrophic lateral sclerosis: a cross-sectional study. Funct Neurol. 2013;28:115-9.

44. Winter Y, Schepelmann K, Spottke AE, Claus D, Grothe C, Schroder R, et al. Health-related quality of life in ALS, myasthenia gravis and facioscapulohumeral muscular dystrophy. J Neurol. 2010;257:1473-81.

45. Ganzini L, Johnston WS, Hoffman WF. Correlates of suffering in amyotrophic lateral sclerosis. Neurology. 1999;52:1434-40.

46. Montel S, Albertini L, Spitz E. Coping strategies in relation to quality of life in amyotrophic lateral sclerosis. Muscle Nerve. 2012;45:131-4.

47. Dal Bello-Haas V, Andrews-Hinders D, Bocian J, Mascha E, Wheeler T, Mitsumoto H. Spiritual well-being of the individual with amyotrophic lateral sclerosis. Amyotroph Lateral Scler Other Motor Neuron Disord. 2000;1:337-41.

48. Langer EJ, Moldoveanu M. The construct of mindfulness. J Social Issues. 2000:56:1-9.

49. Thompson ER. Development and Validation of an International English Big-Five Mini-Markers. Personal Individ Differ. 2008:45:542-8.

50. De Graeff A, de Leeuw JR, Ros WJ, Hordijk GJ, Blijham GH, Winnubst JA. Pretreatment factors predicting quality of life after treatment for head and neck cancer. Head Neck. 2000;22:398-407.

51. Johnston M, Dixon D, Hart J, Glidewell L, Schröder C, Pollard B. Discriminant content validity: a quantitative methodology for assessing content of theory-based measures, with illustrative applications. Br J Health Psychol. 2014;19:240-57.

52. Ware J, Snow KK, Kosinski M, Gandek B. SF-36 Health Survey. Manual and interpretation guide. Boston: The Health Institute, New England Medical Center; 1993.

53. Beck AT, Ward CH, Mendelson M, Mock J, Erbaugh J. An inventory for measuring depression. Arch Gen Psychiatry. 1961:4:561-71.

54. Zigmond AS, Snaith RP. The hospital anxiety and depression scale. Acta Psychiatr Scand. 1983;67:361-70.

55. Pagnini F, Manzoni GM, Tagliaferri A, Gibbons CJ. Depression and disease progression in amyotrophic lateral sclerosis: A comprehensive metaregression analysis. J Health Psychol. 2015;20:1107-28.

56. Gibbons CJ, Mills RJ, Thornton EW, Ealing J, Mitchell JD, Shaw PJ, et al. Rasch analysis of the hospital anxiety and depression scale (HADS) for use in motor neurone disease. Health Qual Life Outcomes. 2011;9:82

57. Yamout B, Issa Z, Herlopian A, El BM, Khalifa A, Ghadieh AS, et al. Predictors of quality of life among multiple sclerosis patients: a comprehensive analysis. Eur J Neurol. 2013;20:756-64. 
58. Paiva CE, Paiva BS, de Castro RA, Souza CP, de Paiva Maia YC, Ayres JA, et al. A pilot study addressing the impact of religious practice on quality of life of breast cancer patients during chemotherapy. J Relig Health. 2013;52:184-93.

59. Mac Donald DA, LeClair L, Holland CJ, Alter A, Friedman HL. A survey of measures of transpersonal constructs. J Transpers Psychol. 1995;27:171-235.

60. Heelas PLF. Expressive spirituality and humanistic expressivism: Sources of significance beyond church and chapel. In: Sutcliffe S, Bowman M, editors. Beyond new age. Exploring alternative spirituality. Edinburgh: Edinburgh University Press; 2000. p. 237-54.

61. Waldron D, O'Boyle CA, Kearney M, Moriarty M, Carney D. Quality-of-life measurement in advanced cancer: assessing the individual. J Clin Oncol. 1999;17:3603-11.

62. Van den Berg JP, de Groot IJ, Joha BC, van Haelst JM, van Gorcom P, Kalmijn S. Development and implementation of the Dutch protocol for rehabilitative management in amyotrophic lateral sclerosis. Amyotroph Lateral Scler Other Motor Neuron Disord. 2004;5:226-9.

63. Hamilton M. The assessment of anxiety states by rating. Br J Med Psychol. 1959;32:50-5.

64. Spielberger CD, Gorsuch RL, Lushene PR, Vagg PR, Jacobs AG. Spielberger State-Trait Anxiety Inventory. Mind Garden: California; 1968.

65. Hamilton M. A rating scale for depression. J Neurol Neurosurg Psychiatry. 1960;23:56-62.

66. Abrahams $\mathrm{S}$, Goldstein LH, Al-Chalabi A, Pickering A, Morris RG, Passingham $R E$, et al. Relation between cognitive dysfunction and pseudobulbar palsy in amyotrophic lateral sclerosis. J Neurol Neurosurg Psychiatry. 1997;62:464-72.

67. American Psychiatric Association. Diagnostic and statistical manual of mental disorders. 4th ed. Washington: American Psychiatric Association; 2000. DSM-IV ed.

68. Zung WW. A self-rating depression scale. Arch Gen Psychiatry. 1965;12:63-70.

69. McNair DM, Lorr M, Droppleman LF. Profile of mood state manual. Educational and Industrial Testing Service: San Diego; 1992.

70. Idler EL. Religious Involvement and the Health of the Elderly: Some Hypotheses and an initial test. Soc Forces. 1987;66:226-38.

71. Reed PG. Spirituality and well-being in terminally ill hospitalized adults. Res Nurs Health. 1987;10:335-44.

72. Ellison CW. Spiritual Well-Being: Conceptualization and Measurement. J Psychol Theol. 1983;2:330-40.

73. Pirson M, Langer EJ, Bodner T, Zilcha-Mano S. The development and validation of the Langer mindfulness scale-enabling a socio-cognitive perspective of mindfulness in organizational contexts. Fordham University Schools of Business Research Paper. 2012. Available at SSRN: http://ssrn. com/abstract=2158921

74. Beck AT, Weissman A, Lester D, Trexler L. The measurement of pessimism: the hopelessness scale. J Consult Clin Psychol. 1974;42:861-5.

75. Zarit SH, Reever KE, Bach-Peterson J. Relatives of the impaired elderly: correlates of feelings of burden. Gerontologist. 1980;20:649-55.

76. Smith CA, Lazarus RS. Appraisal components, core relational themes and the emotions. Cogn Emot. 1993;7:233-69.

77. Carver CS. You want to measure coping but your protocol's too long: consider the brief COPE. Int J Behav Med. 1997:4:92-100.

78. Costa P, McCrae R. Revised NEO Personality Inventory (NEO PI-R) and NEO Five Factor Inventory. Professional Manual. Odessa: Psychological Assessment Resources; 1992.

79. McGee HM, O'Boyle CA, Hickey A, O'Malley K, Joyce CR. Assessing the quality of life of the individual: the SEIQoL with a healthy and a gastroenterology unit population. Psychol Med. 1991;21:749-59.

80. O'Boyle CA, McGee H, Hickey A, O'Malley K, Joyce CR. Individual quality of life in patients undergoing hip replacement. Lancet. 1992;339:1088-91.

81. Hickey AM, Bury G, O'Boyle CA, Bradley F, O'Kelly FD, Shannon W. A new short form individual quality of life measure (SEIQoL-DW): application in a cohort of individuals with HIV/AIDS. BMJ. 1996;313:29-33.

82. Cohen SR, Mount BM, Strobel MG, Bui F. The McGill Quality of Life Questionnaire: a measure of quality of life appropriate for people with advanced disease. A preliminary study of validity and acceptability. Palliat Med. 1995:9:207-19.

83. Cohen SR, Mount BM, Tomas JJ, Mount LF. Existential well-being is an important determinant of quality of life. Evidence from the McGill Quality of Life Questionnaire. Cancer. 1996;77:576-86.
84. Bergner M, Bobbitt RA, Carter WB, Gilson BS. The Sickness Impact Profile: development and final revision of a health status measure. Med Care. 1981;19:787-805.

85. Brazier J, Jones N, Kind P. Testing the validity of the Eurogol and comparing it with the SF-36 health survey questionnaire. Qual Life Res. 1993;2:169-80.

86. Konig HH, Bernert S, Angermeyer MC. Health Status of the German population: results of a representative survey using the EuroQol questionnaire. Gesundheitswesen. 2005;67:173-82.

87. Skevington SM, Lotfy M, O'Connell KA. The World Health Organization's WHOQOL-BREF quality of life assessment: psychometric properties and results of the international field trial. A report from the WHOQOL group. Qual Life Res. 2004;13:299-310.

88. Spitzer WO, Dobson AJ, Hall J, Chesterman E, Levi J, Shepherd R, Battista RN Catchlove BR. Measuring the quality of life of cancer patients: a concise QLindex for use by physicians. J Chronic Dis. 1981;34:585-97.

\section{Submit your next manuscript to BioMed Central and we will help you at every step:}

- We accept pre-submission inquiries

- Our selector tool helps you to find the most relevant journal

- We provide round the clock customer support

- Convenient online submission

- Thorough peer review

- Inclusion in PubMed and all major indexing services

- Maximum visibility for your research

Submit your manuscript at www.biomedcentral.com/submit
C Biomed Central 